\title{
Potencialidades da região do Pampa Gaúcho para o turismo rural
}

The rural tourism potential of Pampas Region in Rio Grande do Sul

\author{
Marcelo Benevenga Sarmento \\ Universidade da Região da Campanha - URCAMP - Bagé - Rio Grande do Sul - Brasil
}

Resumo: Esta pesquisa objetivou investigar o potencial da região do Pampa Gaúcho para o turismo rural. Realizou-se uma pesquisa qualitativa exploratória sobre o potencial turístico dos municípios compreendidos nesta região. Foi realizada uma pesquisa documental inicial seguida de visitas aos municípios. Com base na pesquisa documental e visita aos municípios selecionou-se as atrações potenciais para o turismo regional. As atrações foram separadas em quatro categorias: a)ambiental-paisagístico; b)histórico-arquitetônico; c)econômico-produtivo e, d)sociocultural. Bagé e Caçapava do Sul tiveram o maior número de atrações selecionadas, embora todos os municípios tenham contribuído com pelo menos uma atração. A região do Pampa Gaúcho apresenta grande potencial turístico. O turismo regional mostra-se, dessa forma, como excelente alternativa de geração de renda, empregos, agregação de valor aos produtos e valorização da identidade do gaúcho, constituindo-se em uma forma inovadora de desenvolvimento regional sustentável.

Palavras-chave: Desenvolvimento regional. Turismo rural. Sustentabilidade.

\begin{abstract}
Pampas in Rio Grande do Sul. It was carried out a qualitative exploratory survey in Pampas touristic Region (Aceguá, Bagé, Caçapava do Sul, Candiota, Dom Pedrito, Lavras do Sul, Piratini, Pinheiro Machado and Santana da Boa Vista). Firstly, a documental study was performed following visit to the counties. Based upon documental research and visits to the counties were selected the potential attractions to regional tourism. Attractions were ranked in four categories: a)environmental-landscaping; b)historical-architectonic; c)economic-productive, and, d)sociocultural. Bagé and Caçapava do Sul had the great number of events selected, although all counties contributed with at least one event. Pampas region presents a great touristic potential. Regional tourism exhibits, thus, as an excellent alternative to generate income, jobs, aggregate value to the products and valorizes gaucho's identity, constituting as an innovative way of sustainable regional development.
\end{abstract}

Keywords: Regional development. Rural tourism. Sustainability. 


\section{Introdução}

De acordo com o Ministério do Turismo pode-se entender o turismo rural como "o conjunto das atividades turísticas desenvolvidas no meio rural, comprometidas com a produção agropecuária, agregando valor a produtos e serviços, resgatando e promovendo o patrimônio cultural e natural da comunidade".

Goeldner e Ritchie (2006) argumentam que o ecossistema do turismo comporta redes de organizações que se estendem por realidades espaciais diferentes, conectando múltiplos tipos de atores relacionando diferentes valores, papéis, interesses, capacidades, práticas e distintos recursos e ideias. Desse modo, o turismo é constantemente apresentado como um potencial fator de desenvolvimento econômico para municípios, regiões e países. Porém, como uma atividade múltipla e sendo compreendida como um modo de relações entre pessoas, que permite o desenvolvimento de elos sociais entre os indivíduos, o turismo pode ser estudado sob outro viés, buscando uma dimensão humana e social, focada no desenvolvimento dos processos que contribuam para a sensação de bem-estar (MACHADO e PINENT, 2017).

Moletta (2000) afirma que o turismo rural é uma atividade de lazer que o homem urbano procura junto às propriedades rurais, buscando o contato com a natureza e o resgate de suas origens culturais, bem como a valorização da cultura local. Para o homem do campo, significa uma forma de aumentar a sua renda mensal, valorizando sua propriedade e ao mesmo tempo seu estilo de vida.

Os elementos cotidianos de uma localidade podem ser extremamente atrativos para visitantes que não participam de seu dia-a-dia. Muitos turistas viajam em busca de algo novo e diferente ou, até mesmo, exótico. Dessa forma, o conceito de atrativo turístico varia de turista para turista, já que está relacionado às motivações de viagem e à avaliação que os visitantes fazem desses atrativos (OPPLIGER Et al., 2016).

Os atrativos turísticos segundo Cooper et al (2001) devem ser conceituados como aqueles que compõem a oferta turística, considerada agregada e, que estão, em algum ponto, relacionados com a história e a cultura dos lugares, podendo estes serem prédios, igrejas, ruínas arqueológicas, palácios, casas e até mesmo cidades, sendo caracterizados como atrativos turísticos históricos. Entretanto, há os atrativos construídos com a funcionalidade específica de entretenimento, citando-se como exemplos, os parques temáticos e de lazer, locais destinados ao esporte e a recreação.

Os atrativos turísticos podem ser agrupados como aqueles que são construídos pelo homem e os que são proporcionados pela natureza. Os primeiros incluem, principalmente, os produtos da história e da cultura e também complexos de entretenimento criados artificialmente. Os outros são elementos naturais como a paisagem, o clima e a vegetação (COOPER Et al., 2001).

O turismo como atividade econômica tanto no meio rural como urbano vem proporcionando novas e promissoras alternativas para o desenvolvimento regional sustentável. Seguindo o exemplo de países europeus várias regiões Brasileiras vêm apostando nas suas potencialidades ambientais, produtivas $\mathrm{e}$ socioculturais para atrair pessoas e oferecer seus produtos locais diferenciados. A região turística do Pampa Gaúcho, foco desta pesquisa, possui características ambientais, produtivas e socioculturais diferenciadas. Além destas, a rica história de colonização, guerras cisplatinas entre espanhóis e portugueses e a exuberante arquitetura do Século XIX e início do Século XX podem atrair turistas tanto para áreas urbanas como rurais. Nesse sentido as atividades turísticas podem configurar-se como uma alternativa sustentável para a diversificação produtiva e desenvolvimento 
regional, gerando empregos, renda, agregando valor aos produtos locais e divulgando a região no país e até no exterior. Dessa forma, a pesquisa objetivou realizar uma pesquisa qualitativa exploratória sobre o potencial turístico da região do Pampa Gaúcho, buscando-se destacar as principais atrações e eventos desta região.

\section{Materiais e Métodos}

O estudo baseou-se em uma pesquisa qualitativa exploratória. Foi investigado o potencial turístico dos municípios situados na região turística do Pampa Gaúcho (conforme classificação da Secretaria de Turismo, Esporte e Lazer do Estado do Rio Grande do Sul), (Figura 1), sendo os seguintes: Aceguá, Bagé, Caçapava do Sul, Candiota, Dom Pedrito, Lavras do Sul, Piratini, Pinheiro Machado e Santana da Boa Vista.

Foi feita inicialmente uma pesquisa documental em bases bibliográficas. As bases pesquisadas foram: sites do IBGE, COREDEs, Prefeituras Municipais, Associações Comerciais e
Industriais, SEBRAE, SENAR, Secretaria de Turismo, Esporte e Lazer do Estado do Rio Grande do Sul, artigos científicos, boletins e livros técnicos. Após a pesquisa documental foram realizadas visitas aos municípios, suas atrações e eventos. Foram selecionadas as principais características potenciais para o turismo. As potencialidades turísticas dos municípios pesquisados encontramse no Quadro 1, organizadas e apresentadas em quatro seções: a)Ambiental-paisagístico, b)Histórico-arquitetônico, c)Econômico-produtiva e d)Sociocultural. A seleção das atrações foi independente do município considerado, ou seja, ou municípios tiverem diferente número de atrações selecionadas. A metodologia utilizada nesta pesquisa apresenta-se sintetizada na Figura 2.

Figura 1. Mapa das regiões turísticas do Rio Grande do Sul

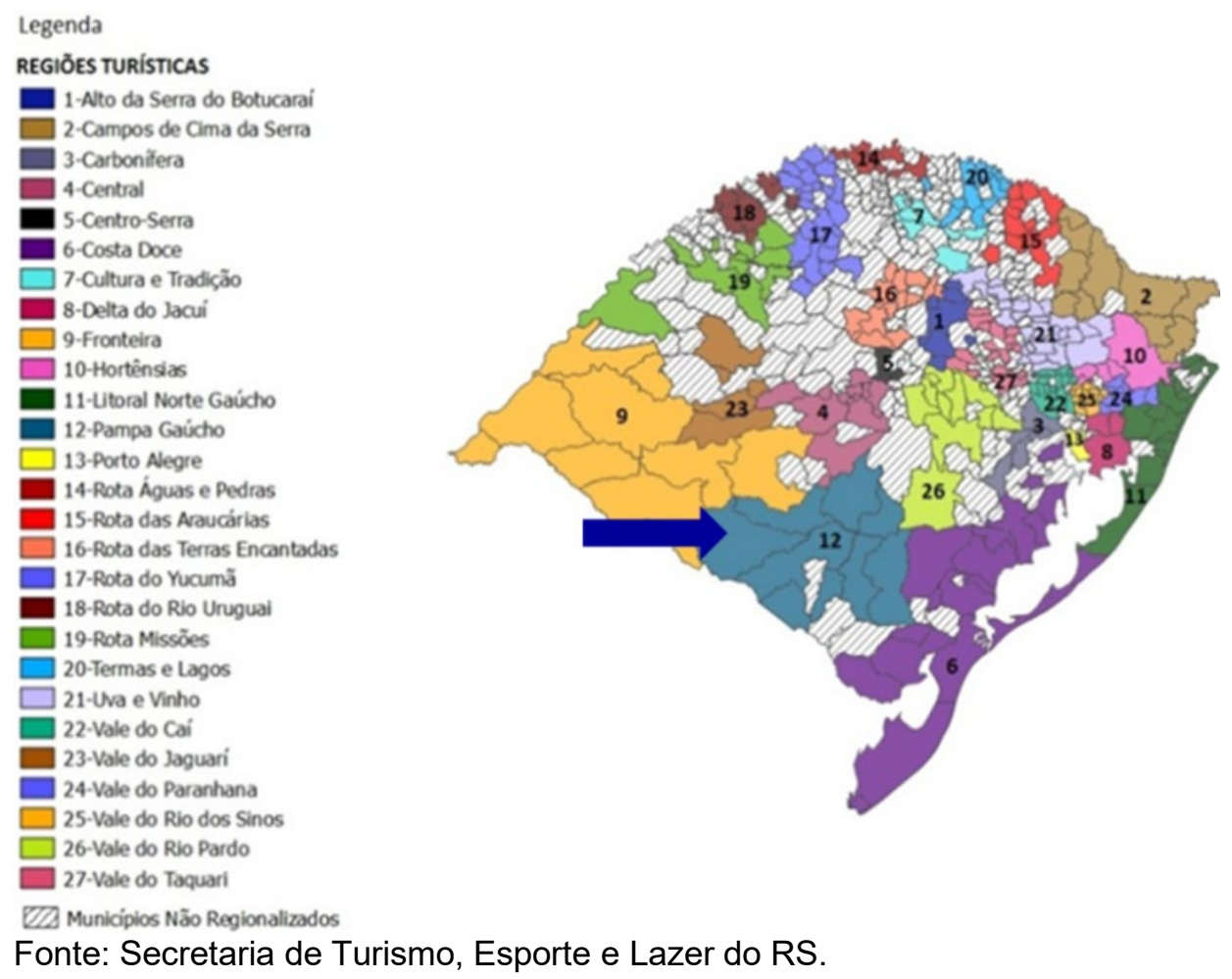


Figura 2. Metodologia utilizada no artigo.

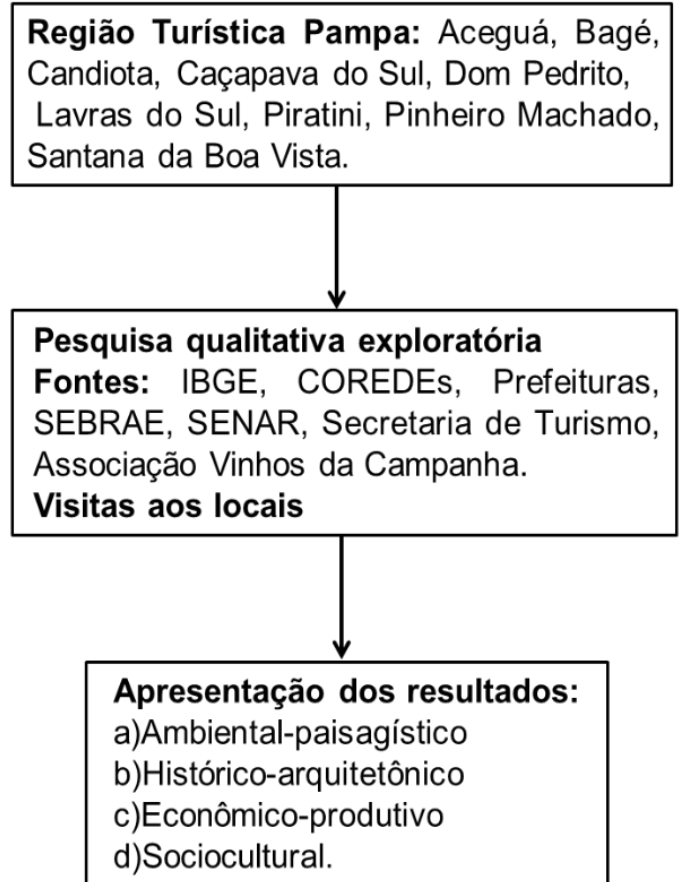

Fonte: Elaboração dos autores

\section{Resultados e Discussão}

\section{Aspectos Ambientais-paisagísticos}

A região do Pampa possui belezas cênicas como o Parque das Guaritas, a Pedra do Segredo em Caçapava do Sul, o Rincão do Inferno, em Bagé, o parque eólico de Cerro Chato em Santana do Livramento e as paisagens campestres. Além destes a rica biodiversidade de fauna e flora e os muitos locais para observação de aves constituemse em atrativos já reconhecidos. As Minas do Camaquã, em Caçapava do Sul, além de um local de belas paisagens e com prédios históricos e um museu, também oferece locais para turismo ecológico e de aventura como rapel, tirolesa, caiaque e arvorismo, dentre outros. O município de Caçapava do Sul destaca-se ainda com o Parque das Guaritas, considerado uma das 7 maravilhas do Rio Grande do Sul. O Parque das Guaritas e as Minas do Camaquã representam uma refúgio ecológico para grande número de espécies animais e vegetais endêmicas além de local para prática de esportes radicais como rapel, escalada, descidas, dentre outros (SARMENTO, 2015).

As paisagens campestres do Pampa Gaúcho também têm chamado a atenção de fotógrafos, roteiristas e cinegrafistas profissionais. A região foi palco de duas grandes séries como: "A casa das 7 mulheres" e "O tempo e o vento", além dos menos conhecidos "Animal, "O Sabiá", "O Guri”, "Valsa para Bruno Stein", dentre outros. No município de Aceguá acontece anualmente o Festival de Balonismo. Em Santana do Livramento, o antigo "Ovino e Vinho", atual Ovinoart, festival regional que reúne gastronomia típica, vinhos, carne e artesanato ovino e apresentações artísticas. Em Pinheiro Machado, há a Fenovinos, renomada feira de importância internacional para os criadores, compradores de genética bem como simpatizantes da ovinocultura (SARMENTO, 2015).

Outro aspecto ambiental da região consiste na diversidade de espécies vegetais. Os campos do Pampa consistem em uma mistura de espécies megatérmicas, de clima quente e microtérmicas, de clima frio, com predomínio das primeiras (BURKART, 1975). Nesta mistura de espécies estão presentes plantas forrageiras das famílias Poaceae e Fabaceae de grande qualidade para a alimentação de animais.

Dentre as espécies da família Poaceae citadas por Boldrini (2012) para o Bioma Pampa encontram-se gêneros de interesse forrageiro como Axonopus, Paspalum, Bromus, Briza, Piptochaetium, Stipa, dentre outras. Pertencentes à família Fabaceae, também são encontrados diversos gêneros relevantes como: Adesmia, Desmodium, Lathyrus, Lupinus Mimosa, Stylosanthes, Trifolium, Vicia, Vigna, dentre muitos outros.

Além das reconhecidas espécies de interesse forrageiro, a diversidade da flora neste bioma abriga ainda espécies cujas flores, frutos ou folhas apresentam características estéticas adequadas para o uso ornamental. As plantas 
nativas no Bioma Pampa têm adaptações morfológicas e fisiológicas que resultam em uma gama de possibilidades para o uso no paisagismo e na arte floral: plantas de sombra ou de sol, para grandes áreas ou pequenos vasos, terrestres ou aquáticos, anuais ou perenes, com longo ou breve período de florescimento, com uma beleza clássica ou inusitada (HEIDEN e IGANCI, 2009).

Considerando o potencial de uso pouco explorado no Brasil, as frutas nativas no Bioma Pampa podem, a médio e longo prazo, se apresentar como alternativas para geração de renda, principalmente em pequenas propriedades rurais, como forma de diversificação. Ao mesmo tempo em que pesquisas sobre espécies de frutas nativas da Região Sul são recentes, vem ocorrendo um aumento da valorização da biodiversidade, que se reflete no crescimento da demanda por produtos derivados, tanto por parte dos consumidores como do setor produtivo, que percebe, a partir desse cenário, o surgimento de novas oportunidades. Dentre as diversas espécies de frutas nativas que ocorrem no Bioma Pampa vem se destacando em diversa pesquisas o araçá, o butiá, a cerejeira do mato, o guabijú, a feijoa e a pitanga (CORADIN et al., 2011).

No Bioma Pampa ocorrem ainda diversas espécies silvestres aparentadas das espécies cultivadas. Um exemplo é uma espécie silvestre de batata (Solanum commersonii), a qual faz parte do pool gênico secundário da batata cultivada (Solanum tuberosum). Esta espécie silvestre é uma importante fonte de genes de resistência a vários estresses bióticos e abióticos que ameaçam o cultivo de batata, como geada, seca, calor, insetos e doenças (CASTRO et al., 2007). Acessos de $S$. commersonii coletados no Bioma Pampa fazem parte do acervo do Banco Ativo de Germoplasma de Batata da Embrapa Clima Temperado, e vem sendo caracterizados para utilização em cruzamentos com genótipos de $S$. tuberosum no programa de melhoramento genético de batata conduzido pela
Embrapa. Outro parente silvestre de uma planta cultivada que ocorre no Bioma Pampa é o Arachis burkartii, pertencente ao mesmo gênero do amendoim (BERTIOLI et al., 2011), é uma espécie rizomatosa com potencial forrageiro. Além destes, Hordeum euclaston e Hordeum stenostachys, parentes silvestres da cevada, também ocorrem no Bioma Pampa (JARDIM BOTÂNICO DO RIO DE JANEIRO, 2012).

\section{Aspectos Histórico-arquitetônicos}

O Quadro um mostra os principais destaques selecionados como potenciais atrações turísticas da região do Pampa Gaúcho.

A região devido às suas marcadas influências dos colonizadores portugueses e espanhóis e as características históricas possui uma arquitetura exuberante. A pecuária com suas charqueadas, como atividade produtiva predominante desde o inicio da ocupação desta região, ao redor de meados do Século XVII, exibe prédios que, uma vez restaurados, podem atrair turistas de outras regiões brasileiras e até do exterior. Igrejas, museus, prefeituras, praças, cemitérios, fazendas, antigos frigoríficos compõem uma acervo histórico-arquitetônico dos mais destacados e ricos do Brasil. Podem-se citar os prédios históricos de Piratini, primeira capital Farroupilha e Caçapava do Sul como destaques importantes. Ainda, o casarão Armour, no Bairro Armour de Santana do Livramento bem como as Igrejas Auxiliadora, Igreja Matriz, a prefeitura municipal, o Museu Dom Diogo de Souza, Museu da Gravura Brasileira, a Casa de Cultura Pedro Wayne e o Centro Administrativo de Bagé também são potenciais atrativos aos turistas. 
Quadro 1. Potencialidades turísticas da região do Pampa Gaúcha, conforme atrações selecionadas na pesquisa bibliográfica, com respectivos munícipios. Fonte dos autores.

\begin{tabular}{|c|c|c|}
\hline Ambiental-Paisagístico & Histórico-Arquitetônico & Econômico-Produtivo \\
\hline $\begin{array}{l}\text { Por do sol nos campos e } \\
\text { serras da região do Pampa }\end{array}$ & $\begin{array}{l}\text { Igreja Matriz de Bagé } \\
\text { Igreja Auxiliadora, Bagé }\end{array}$ & $\begin{array}{l}\text { Feiras } \\
\text { centenárias }\end{array}$ \\
\hline Pastagens naturais da região & $\begin{array}{l}\text { Museu Dom Diogo de Souza, } \\
\text { Bagé }\end{array}$ & Feovelha, Pinheiro Machado \\
\hline $\begin{array}{l}\text { uã, região } \\
\text { Camaquã, região }\end{array}$ & óricos de Caçapava & rod \\
\hline $\begin{array}{l}\text { Biodiversidade de fauna e } \\
\text { flora da região }\end{array}$ & $\begin{array}{l}\text { imoeiro, Bagé. } \\
\text { Sobrado, Bagé }\end{array}$ & Inglês, \\
\hline $\begin{array}{l}\text { Parque das Guaritas, } \\
\text { Caçapava do Sul }\end{array}$ & $\begin{array}{l}\text { Casa de Cultura Pedro Wayne, } \\
\text { Bagé } \\
\text { Vila de Santa Tereza, Bagé }\end{array}$ & $\begin{array}{l}\text { lbú Estância do Vinho, } \\
\text { edrito }\end{array}$ \\
\hline , Bagé, & Prédios & iníce \\
\hline $\begin{array}{l}\text { Festival } \\
\text { Aceguá }\end{array}$ & $\begin{array}{l}\text { Forte Dom Pedro II, Caçapava } \\
\text { do Sul }\end{array}$ & $\begin{array}{l}\text { Cultivo da } \\
\text { municípios }\end{array}$ \\
\hline $\begin{array}{l}\text { Minas do Camaquã, } \\
\text { Caçapava do Sul }\end{array}$ & $\begin{array}{l}\text { Igreja Matriz Nossa Senhora da } \\
\text { Assunção, Caçapava do Sul }\end{array}$ & $\begin{array}{l}\text { Turismo de compras nos free- } \\
\text { shops da região }\end{array}$ \\
\hline egredo, C & Igreja I & $\begin{array}{l}\text { Carnes ovinas e bovinas } \\
\text { diferenciadas }\end{array}$ \\
\hline $\begin{array}{l}\text { Cascata do Salso, Caçapava } \\
\text { do Sul }\end{array}$ & Rua B & $\begin{array}{l}\text { ndicação Geográfica - Carne } \\
\text { do Pampa Gaúcho }\end{array}$ \\
\hline $\begin{array}{l}\text { Cerro Palomas, Santana do } \\
\text { Livramento }\end{array}$ & $\begin{array}{l}\text { Forte Santa Tecla, Bagé. } \\
\text { Museu da Gravura Brasileira, } \\
\text { Bagé }\end{array}$ & $\begin{array}{l}\text { Indicação Geográfica-Vinhos } \\
\text { da campanha (processo no } \\
\text { INPI) }\end{array}$ \\
\hline $\begin{array}{l}\text { Lago Batuva, Santana do } \\
\text { Livramento }\end{array}$ & $\begin{array}{l}\text { Bairro Armour, Santana do } \\
\text { Livramento }\end{array}$ & $\begin{array}{l}\text { Vinícola Miolo, Santana do } \\
\text { Livramento }\end{array}$ \\
\hline $\begin{array}{l}\text { Parque Eólico de Santana do } \\
\text { Livramento }\end{array}$ & $\begin{array}{l}\text { Museu Histórico Farroupilha, } \\
\text { Piratini }\end{array}$ & $\begin{array}{l}\text { Artesanato e produtos típicos } \\
\text { feitos em lã e couro }\end{array}$ \\
\hline $\begin{array}{lcc}\text { Parque Toca da } & \text { Tigre, } \\
\text { Santana da Boa Vista } & \end{array}$ & Museu Barbosa Lessa, Piratini & $\begin{array}{l}\text { Estância e Vinícola Paraizo, } \\
\text { Bagé }\end{array}$ \\
\hline Observatórios para fauna e & $\begin{array}{l}\text { Cemi } \\
\text { Centr }\end{array}$ & $\begin{array}{l}\text { Estância Artigas, } S \\
\text { Livramento }\end{array}$ \\
\hline \multicolumn{3}{|c|}{ Sociocultural } \\
\hline $\begin{array}{l}\text { Riqueza étnica de povos de } \\
\text { origem indígena, quilombola, } \\
\text { espanhola, portuguesa e } \\
\text { alemã. }\end{array}$ & $\begin{array}{l}\text { Artesanato em lã, couro, fibras e } \\
\text { gastronomia caseira oriundos da } \\
\text { agricultura familiar, território do } \\
\text { Alto Camaquã, Caçapava do Sul. } \\
\end{array}$ & dos os \\
\hline $\begin{array}{l}\text { Festivais musicais: } \\
\text { Galponeira de Bagé, } \\
\text { Ponche Verde da Can } \\
\text { Dom Pedrito. }\end{array}$ & \begin{tabular}{|lrr} 
Festival & Ovino e & Vinho \\
(Ovinoart), & Santana & do \\
Livramento. & & \\
\end{tabular} & $\begin{array}{l}\text { Festival Internacional de } \\
\text { Música do Pampa, Bagé. } \\
\text { Festival Internacional de } \\
\text { Cinema de Fronteira, Bagé. } \\
\end{array}$ \\
\hline $\begin{array}{l}\text { Motobagé, Bagé } \\
\text { Festival da Cerveja Artesanal, } \\
\text { Bagé }\end{array}$ & ras, Lavras do Sul & $\begin{array}{l}\text { Festival Binacional de } \\
\text { Enogastronomia e Produtos } \\
\text { do Pampa, Santana do } \\
\text { Livramento }\end{array}$ \\
\hline
\end{tabular}

\section{Aspectos Econômico-produtivos}

A principal atividade econômica da região, há mais de três séculos, é a pecuária extensiva com base em campo nativo. O campo nativo da região é composto por uma grande diversidade de famílias botânicas de importância agronômica, destacando- se as gramíneas e leguminosas de alta qualidade forrageira e que compõem uma excelente dieta para a criação de animais.

Na pecuária bovina de corte pesquisas tem demonstrado que animais criados em campo nativo ou melhorado possuem alta relação ômega 6ômega 3 e alto teor de ácido linoleico conjugado, 
características estas que tornam a carne destes animais de qualidade nutricional equivalente a peixes como o salmão. Além disso, a carne bovina possui elevada composição em vitaminas do complexo $B$, zinco, ferro, magnésio, selênio e antioxidantes (FREITAS et al. 2014; LOBATO et al., 2014). A carne ovina proveniente de animais criados exclusivamente a pasto possui características sensoriais desejáveis (saborosa, macia e suculenta), além disso, pesquisas demonstram que ovinos criados nesse sistema possuem carne com elevação no teor de ácidos graxos poli saturados, como ácido linolênico e ácido vacênico, considerados benéficos a saúde humana (SACCOL, 2015).

O Pampa destaca-se ainda na criação de raças ovinas, bovinas e equinas com grande adaptabilidade ao clima, solo e sistemas produtivos da região. Os animais oriundos da região têm obtido destaque nas principais Exposições-feiras nacionais e internacionais devido às diferenciadas características zootécnicas, entre elas, alta qualidade genética.

A pecuária com base em campo natural também possui relevantes vantagens ambientais, pois, preserva o campo natural e as espécies vegetais e animais a ele associadas (Lobato et al.,2014; Ruviaro et al., 2016). Estes campos ainda podem fornecer inúmeros serviços ecossistêmicos. São exemplos a regulação hídrica e o fornecimento de água limpa, a produção de forragem para a atividade pecuária, a manutenção de polinizadores e de predadores de pragas de culturas agrícolas, o potencial para a recreação ao ar livre, a estocagem de carbono no solo que ajuda a mitigar as mudanças climáticas globais, dentre tantos outros (PILLAR et al., 2015).

Para Lobato et al. (2014), a criação pecuária no Bioma Pampa é essencial para a sua conservação e sustentabilidade. Neste ecossistema, cujos produtos animais são obtidos a partir de sistemas de produção baseados em pastagens naturais, o valor não está apenas no fornecimento de alimento, mas também no suprimento dos serviços ambientais e sequestro do carbono atmosférico.

Para que os diferenciais acima citados possam ser reconhecidos e valorizados é necessária a certificação de produtos e processos de produção diferenciados. Alguns exemplos de certificação têm sido obtidos objetivando diferenciar estes produtos e agregar valor à carne do Pampa. Um case é a Indicação Geográfica Carne do Pampa Gaúcho da Campanha Meridional, que foi criada em 2006 para bovinos de origem europeia e suas respectivas cruzas criados em pastagens naturais e/ou melhoradas. Em setembro de 2015 foi lançado o Selo do frigorífico Marfrig e Alianza del Pastizal para a certificação de carne produzida em campo nativo bem conservado. Outra certificação da qual também fazem parte os animais produzidos na Campanha Gaúcha é o selo Cordeiro Gaúcho, que integra o Programa de Desenvolvimento da Ovinocultura Gaúcha, lançado pela Associação Brasileira dos Criadores de Ovinos (ARCO).

Além da pecuária, o cultivo de espécies perenes como florestais e frutíferas de clima temperado também vem sendo incentivado na região. Devido às condições edafoclimáticas favoráveis, tais condições propiciam ainda, no Pampa, a produção de vinhos, espumantes e azeites de oliva de qualidade comparável às melhores regiões produtoras do mundo. Além disso, outros setores podem ser beneficiados pelo desenvolvimento dessas atividades, como o turismo, comércio e a gastronomia, o que multiplica várias vezes os seus benefícios na direção do desenvolvimento sustentável da região pampeana.

Santana (2016) argumenta que diversas atividades podem conviver harmonicamente com os ambientes campestres no Pampa gaúcho sem trazer grandes impactos ao meio, seja pela pouca área que requerem, seja por utilizarem modelos produtivos que não alteram drasticamente a 
paisagem. A vitivinicultura e a produção de oliveiras, com suas cadeias agroindustriais associadas, são bons exemplos de convivência harmônica entre atividades produtivas e conservação ambiental, conforme o autor.

Em relação ao enoturismo, houve nos últimos 14 anos grandes investimentos em plantios de vinhedos para produção de vinhos finos e na construção de vinícolas. Estas têm atraído turistas de outras regiões do estado, de outros estados e também do exterior. O principal atrativo consiste na degustação dos vinhos e espumantes regionais acompanhados das também renomadas carnes bovinas e de cordeiro do pampa gaúcho ao mesmo tempo em que é possível visualizar as belas paisagens do Pampa ao entardecer. Cenários que tem inspirado poetas, escritores e diretores de cinema. Porém, as vinícolas precisam investir mais na infraestrutura para uma melhor acolhida de turistas, enfatizando um bom atendimento aos mesmos, com bons programas de passeio e visitações, além das já citadas degustações. É preciso também uma maior divulgação do turismo da região, não sendo apenas o enoturismo como motivação para tal, mas focando também nas demais atrações históricas, culturais e feiras agropecuárias existentes nesta região (SARMENTO, 2017).

As principais rotas enoturísticas partindo de Porto Alegre ou Santa Maria, podem ser visualizadas no mapa abaixo (Figura 3), embora nem todos os municípios mostrados no mapa façam parte da região Turística do Pampa Gaúcho, porém, parte de suas rotas passam pelos municípios da região pesquisada neste artigo (Associação dos Vinhos da Campanha).
Figura 3. Mapa da Região da Campanha Gaúcha com as rotas enoturísticas em destaque (Associação dos Vinhos da Campanha).

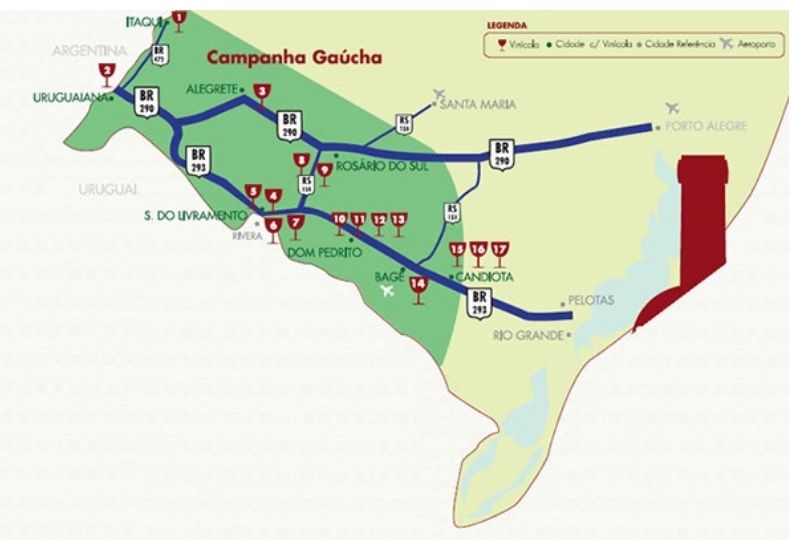

Dentre as características potenciais para o turismo regional, a sustentabilidade da viticultura regional também poderia ser destacada como ponto diferenciado na atração de turistas e como referencial importante para a obtenção de Indicação de Procedência. Nesse sentido, os vitivinicultores da região da Campanha têm procurado conciliar a produção e a qualidade das uvas com a preservação do Bioma Pampa, como um dos pontos relevantes para busca da Indicação Geográfica. Está em andamento, no INPI, um projeto para registro da Indicação Geográfica Vinhos da Campanha, com isso, a vitivinicultura poderia ser inserida nesse ambiente sem alteração significativa da paisagem e minimizando os processos de degradação pelas demais atividades agrícolas (SARMENTO, 2015).

A percepção de que o vinho pode ser fator de permanência cultural, visto a partir de uma ideologia, como fator de expressão da identidade e dos hábitos alimentares de sua região produtora (ou de quem o produz), justifica a percepção do enoturismo como facilitador do desenvolvimento regional por meio da "venda" do território turístico a partir de sua própria origem e identidade cultural (PEREIRA e LOSSO, 2012).

Há ainda produtos regionais como a carne bovina e o cordeiro do pampa, ambos cuja qualidade é bastante reconhecida, ultrapassando 
limites regionais. Além destes, os produtos artesanais da agricultura familiar são de qualidade e sabor diferenciados. Destacam-se ainda 0 artesanato de lã ovina e caprina e os pães caseiros, geleias, sucos, iogurtes e queijos oriundos da agricultura familiar dos municípios de Aceguá, Bagé, Candiota, Caçapava do Sul e Hulha Negra (SARMENTO, 2015).

\section{Aspectos socioculturais}

A região do pampa tem uma grande riqueza histórica e sociocultural, sendo um dos maiores exemplos os "Gauchos", tradicional homem rural do Sul do Brasil, Uruguai e Argentina, estreitamente relacionado ao campo, cavalos e gado. Esta figura tem uma ampla gama de costumes, indumentária típica e artesanato feito com base no couro e lã dos animais criados nas pastagens naturais. Esta enorme riqueza de cultura e arte deve ser conservada e uma das formas é via sistemas de produção sustentáveis (DE BOEF e THIJSSEN, 2013).

A identidade do bioma Pampa com a cultura gaúcha é reveladora da intersecção de várias etnias. Este encontro étnico se revela não só pelos registros históricos, mas também, pelo legado cultural crioulo expresso na linguagem (SUERTEGARAY e SILVA, 2012).

Ainda, é possível destacar que a região foi palco de acontecimentos históricos importantes como a chegada dos jesuítas, a Guerra dos Farrapos, as Guerras Cisplatinas, os quais foram relatados em diversos livros, filmes e séries. Tais exemplos constituem-se em uma riqueza histórica e sociocultural da região do Pampa Gaúcho e ainda pouco explorada, merecendo ser mais bem estudada e valorizada.

A região do Pampa Gaúcho, embora apresente gargalos logísticos, sociais, mercadológicos e político-institucionais importantes, possui potencialidades culturais, históricas, ambientais e agrícolas que, se bem organizadas, podem transformar a realidade, construindo um desenvolvimento regional sustentável que promova melhoria na renda, geração de empregos e diversificação da matriz produtiva, traduzindo-se na inserção dos agricultores nas cadeias produtivas e no incremento do bem-estar social e qualidade de vida de toda a população. A riqueza sociocultural, ambiental e paisagística bem como a vitivinicultura poderia ser reunida em um grande projeto de longo prazo para constituir um Arranjo Produtivo Local (APL). Este APL deve fundamentar-se nas noções de endogeneidade (recursos locais), territorialidade (relação homem-espaço) e institucionalidade (organizações de apoio, associações, cooperativas, instituições públicas e privadas).

\section{Conclusões}

Nos últimos anos, a busca por locais campestres, paisagens pitorescas e comida caseira têm sido crescente na população urbana brasileira e mundial. A região turística do Pampa apresenta condições ambientais-paisagísticas, históricoarquitetônicas, econômico-comerciais e socioambientais impares, que, se bem promovidas em um projeto de longo prazo podem se constituir em diferenciais para o desenvolvimento regional sustentável.

O Pampa apresenta características potencialmente interessantes que podem alavancar o desenvolvimento regional. $\mathrm{O}$ turismo tanto rural como urbano também podem contribuir para a diversificação da matriz produtiva regional, historicamente dependente de produtos primários oriundos da agropecuária.

Além do meio ambiente em bom estado de conservação, das belas paisagens rurais, prédios e monumentos de relevância histórico-arquitetônica a região é também conhecida como produtora de 
carne ovina e bovina de alta qualidade, cuja base produtiva é o campo nativo conservado. Este mesmo campo além de produzir carne sustentável e saudável, contribui para a geração de inúmeros serviços ecossistêmicos como manutenção dos cursos d'água e aquíferos, sequestro de carbono atmosférico, redução da erosão do solo, conservação da fauna e flora e preservação da identidade do gaúcho. Ainda a figura mítica do Gaúcho destaca-se pela relação íntima com a terra e com os animais, constituindo-se em uma grande riqueza artística, cultural e gastronômica.

Como atrações adicionais, o enoturismo, ecoturismo, território do Alto Camaquã, turismo de compras nas fronteiras e os festivais culturais são temas que devem ser mais bem explorados.

O potencial turístico da região precisa ser fortalecido com parcerias público-privadas visando à melhoria na infraestrutura hoteleira, estradas, gastronomia e restauração de locais históricos. Além disso, a elaboração de produtos alimentares e artesanais típicos também podem se constituir em atrativos aos turistas. A adequação da oferta à demanda e ao perfil do turista também é fundamental para que o potencial turístico do Pampa possa se desenvolver de forma sustentável. A escolha de produtos típicos representativos da região como, por exemplo, as carnes ovina e bovina, o arroz, o vinho e o óleo de oliva associados a uma marca coletiva ou certificação podem constituir ótimos exemplos para a divulgação da imagem da região no Brasil e no exterior.

Em um contexto nacional e global de busca por novos e pitorescos locais para entretenimento, gastronomia e atividades ao ar livre a região do Pampa Gaúcho pode oferecer um turismo rural diferenciado de outros locais, contribuindo para a geração de empregos, renda, agregação de valor aos produtos caseiros e desenvolvimento regional sustentável.

\section{Referências}

ASSOCIAÇÃO VINHOS DA CAMPANHA. Disponível em: http://www.vinhosdacampanha.com.br. Acesso em: 06/02/2018.

BOLDRINI, I.I. A flora dos Campos do Rio Grande do Sul. In: Pillar, V.P.; Müller, S.C.; Castilhos, Z.M.S et al. (Eds.). Campos Sulinosconservação e uso sustentável da biodiversidade. Brasília: MMA, 2012. p.63-77.

BERTIOLI, D.J.; SEIJO, G.; FREITAS, F.O.; VALLS, J.F.M.; LEAL-BERTIOLI, S.C.M.; MORETZSOHN, M.C. An overview of peanut and its wild relatives. Plant genetic resources: characterization and utilization, v. 9, p. 134149, 2011.

BURKART, A. Evolution of grasses and grasslands in South America. Taxon, v.24, p.53-66, 1975.

COOPER, C.; FLETCHER, J.; FYALL, A.; GILBERT, D.; WANHILL, S. Turismo, princípios e prática. 2. Ed. Porto Alegre: Bookman. 2001.

CASTRO, C.M.; PEREIRA, A.S.; COSTA, D.; CHOER, E.; AUGUSTIN, E.; GOMES, C.B.; CAMPOS, A.D.; OLIVEIRA, R.P.; GARRASTAZÚ, M.C.; BARBIERI, R.L.; MENTZ, L.; VIÉGAS, J. Wild potato genetic resources conserved in Southern Brazil: current knowledge and future perspectives. Acta Horticulturae, v. 745, p. 323-330, 2007.

CORADIN, L.; SIMINSKI. A.; REIS, A. Eds. Espécies Nativas da Flora Brasileira de Valor Econômico atual ou Potencial Plantas para o Futuro - Região Sul. Ministério do Meio Ambiente/MMA. Brasília, DF. 2011. 634p.

DE BOEF, W.S.; THIJSSEN, M. Community biodiversity management and in situ conservation of plant genetic resources. In: Community Biodiversity Management: Promoting Resilience and the Conservation of Plant Genetic Resources: De Boef, W.S.; SUBEDI, A.; PERONI, N.; THIJSSEN, M.; O'KEEFFE, E.;Eds.; Routledge: Wageningen, The Netherlands, pp. 51-61. 2013.

FREITAS, A. K. DE; LOBATO, J. F.; CARDOSO, L. L.; TAROUCO, J. U.; VIEIRA, R.M.; DILLENBURG, D. R. Nutritional composition of the meat of Hereford and Braford steers finished on pastures or in a feedlot in southern Brazil. Meat Science 2014, 96(1), 353-360. 
GOELDNER, R.; RITCHIE, B. Tourism: Principles, Practices, Philosophies. Hoboken (NJ), John Wiley \& Sons, (10th ed.). 2006.

HEIDEN, G.; IGANCI, J. R. V. Valorizando a flora nativa. p. 36-43. In: STUMPF, E.R.T.; BARBIERI, L.; HEIDEN, G. (Eds.). Cores e formas no Bioma Pampa - plantas ornamentais nativas. Pelotas: Embrapa Clima Temperado. 2009.

JARDIM BOTÂNICO DO RIO DE JANEIRO. Lista de espécies da flora do Brasil. 2012. Disponível em: <http://floradobrasil.jbrj.gov.br/2012/FB01438 4>. Acesso em 29 ago. 2012.

LOBATO, J.F.P; FREITAS, A.K.; DEVINCENZI, T.; CARDOSO, L.L.; TAROUCO, J.U.; VIEIRA, R.M.; DILLENBURG, D.R.; CASTRO, I. Brazilian beef produced on pastures: Sustainable and healthy. Meat Science 98 (2014) 336-345.

MACHADO, A.L. de M.; PINENT, M.A.P. O turismo de bem-estar como possibilidade de desenvolvimento de um cluster turístico: a proposta do Vale Do Paranhana, Rio Grande do Sul. Ágora. Santa Cruz do Sul, v.19, n. 02, p. 54-66, jul./dez. 2017.

MATOS, M. Governança e Políticas Públicas em Territórios de Baixa Densidade. Dissertação

de Mestrado. Lisboa: ISCTE-IUL. 2013. Acessível em https://repositorio.iscte-iul.pt/bitstream/10071/7357/1/Dissertacao\%2 0Concei\%C3\%A7aoMatos\%20\%20Governa n\%C3\%A7a\%20e\%20PP\%20em\%20TBD\% 20-\%20Sem\%20CV.pdf.

OPPLIGER, E.A.; FONTOURA, F.M.; OLIVEIRA, A.K.M.; TOLEDO, M.C.B.; SILVA, M.H.S.; GUEDES, N.M.R. O potencial turístico para a observação da avifauna em três áreas verdes na cidade de Campo Grande, MS. Revista Brasileira de Pesquisa em

Turismo. São Paulo, 10(2), pp. 274-292, maio/ago. 2016.

MINISTÉRIO DO TURISMO. Disponível em <http://www.turismo.gov.br/turismo/ programas_acoes/regionalizacao_turismo/es truturacao_segmentos/rural.html> Acesso em: 15 de fevereiro de 2018.

MOLETTA, V. F. Turismo Rural. 2a . Ed. Porto Alegre: SEBRAE/RS Editora, 2000.

PILLAR, V. DE. P.; ANDRADE, B.O; DADALT, L. Serviços ecossistêmicos. In: PILLAR; V. DE P.; LANGE, O. Eds. Os Campos do Sul. Editora da UFRGS, Porto Alegre: Rede Campos Sulinos, Porto Alegre, 192p. 2015.
PEREIRA, R.M.F. do A.; LOSSO, F.B. O desenvolvimento da vitivinicultura $e$ as possibilidades de implantação de roteiros enoturísticos na Região de São Joaquim (SC, Brasil). Revista Brasileira de Pesquisa em Turismo. São Paulo, 6(2), pp. 181-200, mai./ago. 2012.

RUVIARO, C.F; COSTA, J.S.DA; FLORINDO, T.J.; RODRIGUES, W.; MEDEIROS, G.I.B.DE; VASCONCELOS, P.S. Economic and environmental feasibility of beef production in different feed management systems in the Pampa biome, southern Brazil. Ecological Indicators 60. 2016, p930-939.

SACCOL, A. G. F. Produção de carne ovina em diferentes sistemas de alimentação. TESE, Universidade Federal de Santa Maria, UFSM, Santa Maria, p. 122-134, 2015.

SANTANA, D.M. Atividades Produtivas. In: CHOMENKO, L.; BENCKE, G.A. Nosso Pampa Desconhecido. Porto Alegre: Fundação Zoobotânica do Rio Grande do Sul,p.168-187, 2016.

SARMENTO, M.B. Potencialidades Bioeconômicas da região do Pampa Gaúcho In: BRUCH, K.L; SOUTO, J.M.M.; BORGES, M.C. Orgs. Anais do $3^{\circ}$ Simpósio da Ciência do Agronegócio. CEPAN:UFRGS, Porto Alegre, RS, Nov., 2015, 790p.

SARMENTO, M.B. Diagnóstico da cadeia da vitivinicultura na Campanha Gaúcha, subdivisão Fronteira Uruguai, Rio Grande do Sul. Trabalho de Conclusão do MBA em Gestão do Agronegócio. Universidade Federal do Paraná, PECCA, Educação Continuada, 2014, 72p.

Secretaria de Turismo, Esporte e Lazer do Rio Grande do Sul. Disponível em: http:// http://www.turismo.rs.gov.br/inicial. Acesso em: 06/02/2018.

SUERTEGARAY, D.M.A; SILVA, L.A.P.DA. Tchê Pampa: histórias da natureza gaúcha. In: Pillar, V.P.; Müller, S.C.; Castilhos, Z.M.S et al. (Eds.). Campos Sulinos- conservação e uso sustentável da biodiversidade. Brasília: MMA, 2012. p.42-62. 